\title{
Review
}

Epidemiology

Diabetes Metab J 2014;38:252-260

http://dx.doi.org/10.4093/dmj.2014.38.4.252

pISSN 2233-6079 • eISSN 2233-6087

DIABET\&S \& METABOLISM JOURNAL

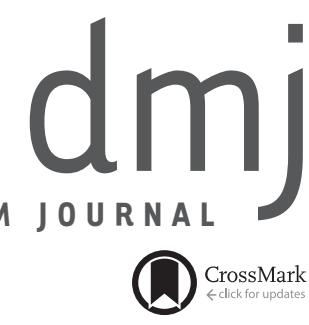

\section{Diabetic Kidney Disease: From Epidemiology to Clinical Perspectives}

\author{
Cheol Whee Park \\ Division of Nephrology, Department of Internal Medicine, The Catholic University of Korea College of Medicine, Seoul, Korea
}

\begin{abstract}
With worldwide epidemic of diabetes mellitus, diabetic nephropathy which is one of the major causes of microvascular complication has become a serious concern in Korea as well as the rest of the world. In view of its significance, there is an urgent and paramount need for proper managements that could either deter or slow the progression of diabetic nephropathy. Despite advances in care, ever increasing number of patients suffering from diabetic kidney disease and from end-stage renal disease implies that the current management is not adequate in many aspects. The reasons for these inadequacies compromise lack of early diagnosis, failure to intervene with timely and aggressive manner, and lack of understanding on the kind of interventions required. Another issue equally important for the adequate care of patients with diabetic nephropathy is an understanding of past, present and future epidemiology of diabetic nephropathy which serves, especially in Korea, as a material determining standard diagnosis and treatment and a national health-policy decision.
\end{abstract}

Keywords: Cardiovascular disorder; Diabetic nephropathies; Renal insufficiency, chronic; Renal replacement therapy

\section{INTRODUCTION}

Chronic kidney disease (CKD) has become a global health care problem. The cost of health services for patients with CKD is 1.8 times higher compared to patients without CKD [1]. The average cost for a dialysis patient is 10.3 times more than that of a non-CKD patient [1]. CKD is one of the widely recognized and notorious indicators for hospitalization, cardiovascular events, cardiovascular and noncardiac mortality, and all-cause of mortality [2,3]. CKD also affects cognitive impairment and quality of life $[4,5]$. Unfortunately, there is a dispute and it is unclear whether the rates of CKD in Korea are consistently increasing or not. In contrast, there is a clear result that the number of patients with end-stage renal disease (ESRD) undergoing dialysis is on the rise among Koreans which is the main contributor to the increasing prevalence of diabetic kidney disease (DKD) [6]. It is evident that the pro- gression of renal failure continues in DKD despite tight and early glucose control, tight blood pressure control as well as aggressive renin-angiotensin-aldosterone (RAA) blockade. This review summarizes what is known about the epidemiology of CKD and DKD among Korean adults and discusses some of the clinically important challenges associated with the diagnosis of DKD.

\section{HOW PREVALENT IS CKD?}

As CKD patients are identified as a group of patients exposed to high risk for death with high rate of comorbidities, it is justifiable to call for careful study and close attention to the management of risk factor [1]. CKD (estimated glomerular filtration rate $[\mathrm{eGFR}]<60 \mathrm{~mL} / \mathrm{min} / 1.73 \mathrm{~m}^{2}$ or urine albumin-creatinine ratio $>30 \mathrm{mg} / \mathrm{g}$ ) is estimated to affect $13.1 \%$ of the United States (US) population, according to the 2012 US Re-
Corresponding author: Cheol Whee Park

Division of Nephrology, Department of Internal Medicine, Seoul St. Mary's

Hospital, The Catholic University of Korea College of Medicine, 222

Banpo-daero, Seocho-gu, Seoul 137-701, Korea

E-mail: cheolwhee@hanmail.net
This is an Open Access article distributed under the terms of the Creative Commons Attribution Non-Commercial License (http://creativecommons.org/licenses/by-nc/3.0/) which permits unrestricted non-commercial use, distribution, and reproduction in any medium, provided the original work is properly cited. 
nal Data Systems report $[7,8]$. Diabetes is the most prevalent cause of ESRD and is also the major cause for $40.4 \%$ of newly developed ESRD in the US, followed by hypertension in the cohort in 2005 to 2010 [7,8]. In the Australian Diabetes, Obesity, and Lifestyle Study, $16.0 \%$ of the study population had one or more indicators of CKD, such as impaired kidney function, hematuria, or proteinuria [9]. As far as the prevalence of $\mathrm{CKD}$ in the Asian population is concerned, it is reported to be $12.9 \%$ in Japan [10] and $13.0 \%$ in Beijing (Fig. 1) [11]. There were no big differences in the prevalence of CKD among the various countries. Interestingly, the CKD prevalence in the US has increased from $10.0 \%$ on National Health and Nutritional Examination Survey (NHANES) III (1988 to 1994) to 13.1\% on NHANES 1999 to 2004 [8]. A recent study from Japan also showed that the overall CKD prevalence among the Japanese male has increased from $13.8 \%$ in 1974 to $22.1 \%$ in 2002 and it was attributed to increase in diabetes, hypercholesterolemia, and obesity over the three decades in males [12].

In contrast to other countries, the CKD prevalence in the Korean adult population has not been well known. According to Chin [13], the prevalence of CKD in Korean adult population has decreased from $12.4 \%$ in 2006 to $10.2 \%$ in 2008 (Fig. 1). However, the study was conducted in two tertiary hospitals and it could not explain the reason for the decrease in the prevalence. A recent study also reported that the prevalence of CKD in Korean adults in 2009 to be $4.5 \%$ in men and $6.3 \%$ in women citing data from the Korea National Health and Nutritional Examination Survey (KNHANES) IV [14]. The authors, however, did not compare the prevalence of CKD by diabetes status, nor did they investigate the determinants of CKD. The KNHANES V, conducted in 2011 has defined albuminuria (a spot urine albumin/creatinine ratio $>30 \mathrm{mg} / \mathrm{g}$ ) and CKD (eGFR

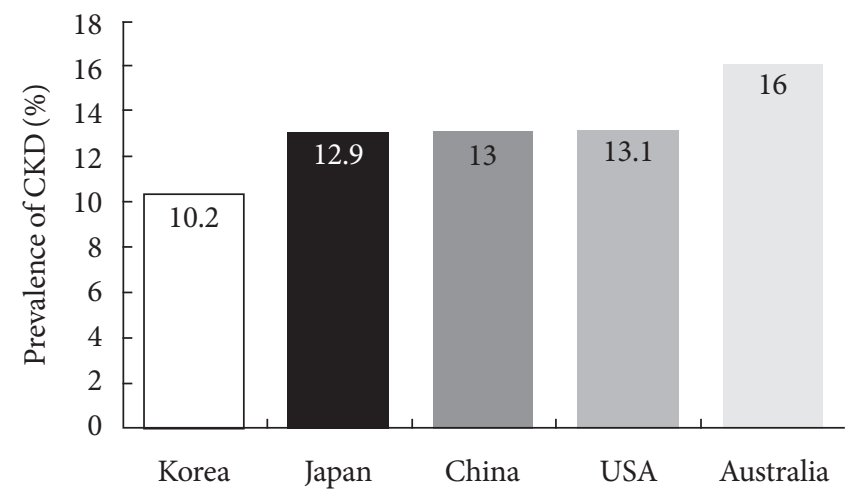

Fig. 1. The prevalence of chronic kidney disease (CKD) in Korea, Japan, China, USA, and Australia in 2008. $\left.<60 \mathrm{~mL} / \mathrm{min} / 1.73 \mathrm{~m}^{2}\right)$. The prevalences of microalbuminuria, macroalbuminuria, and CKD among patients without diabetes were $9.4 \%, 0.8 \%$, and $1.7 \%$, respectively. In contrast, the prevalences of microalbuminuria, macroalbuminuria, and CKD among patients with diabetes were $22.0 \%, 4.6 \%$, and $8.6 \%$, respectively [15]. In patients without diabetes, the overall prevalence of CKD including albuminuria and decreased eGFR was $11.9 \%$ and the prevalence in patients with diabetes was $35.2 \%$. Korean adults with diabetes are exposed to the risk of CKD three times more than the nondiabetic adults, suggesting that diabetes is associated with an approximately 3.0 -fold increased risk of CKD [15]. Epidemiological studies based on diabetes as the primary renal disease must be interpreted with caution [16] as renal biopsies are performed in less than $10 \%$ to $20 \%$ of diabetic patients and thus many of nephropathies are determined by clinical evaluation based on nephrologists' clinical experiences [17].

\section{HOW PREVALENT IS DKD?}

Diabetic nephropathy is associated with an increased risk of CKD, which is characterized by albuminuria or reduced eGFR. Estimates of the prevalence of DKD vary widely. It ranges from $10 \%$ to $40 \%$ for both type 1 and type 2 diabetes patient groups depending on the definition of the disease used $[18,19]$. The prevalence of albumiuria varies with ethnicity with higher rates reported in Asians as compared to Caucasians $[20,21]$. Unfortunately, the prevalence of type 2 diabetes has increased worldwide including Korea [22,23]. Data from the Centers for Disease Control and Prevention (CDC) report that there are approximately 22 million people in the US with diabetes [24]. Moreover, the CDC estimates that one in three adults in the US will have diabetes by 2050 if the current trends continue. According to the numbers from NHANUS III report, $19.3 \%$ of diabetes had eGFRs $<60 \mathrm{~mL} / \mathrm{min} / 1.73 \mathrm{~m}^{2}$, $29.9 \%$ had urine albumin-creatinine ratios $>30 \mathrm{mg} / \mathrm{g}$, and $8.6 \%$ of all patients with diabetes had both [24]. For those with hypertension and without diabetes, the reported prevalence of eGFRs $<60 \mathrm{~mL} / \mathrm{min} / 1.73 \mathrm{~m}^{2}$, and urine albumin-creatinine ratios $>30 \mathrm{mg} / \mathrm{g}$, and both were $12.9 \%, 24.8 \%$, and $4.1 \%$, respectively [9].

According to the recent study, the prevalence of diabetes and prediabetes in Korea were $10.5 \%$ and $19.3 \%$, respectively [25]. In the US, the NHANES III reported that the prevalences of microalbuminuria and macroalbuminuria among adults 
with type 2 diabetes aged $\geq 40$ years were $35 \%$ and $6 \%$, respectively [8]. Based on the study in 930 patients with type 2 diabetes, the Shanghai Diabetic Complications Study reported that the prevalences of microalbuminuria and macroalbuminuria were $22.8 \%$ and $3.4 \%$, respectively [26]. According to the KNHANES V in 2011, which conducted survey on measured albuminuria for the first time, the prevalence of microalbuminuria, macroalbuminuria, and CKD were $22.0 \%, 4.7 \%$, and $8.6 \%$, respectively [15]. Other studies have shown slightly different results. In a single center study conducted in 1995 including 631 Korean patients with type 2 diabetes, the prevalence of albuminuria was $34 \%$ (20\%, microalbuminuria; $14 \%$, macroalbuminuria) [27] as compared to another study in 2011 on 3,738 patients with type 2 diabetes and hypertension [28], showing $29.4 \%$ (23.1\%, microalbuminuria; $6.3 \%$, macroalbuminuria) of the prevalence.

The prevalence of CKD in patients with type 2 diabetes in the KNHANES V was $8.6 \%$ which is much lower than that in Western populations as well as in other East Asian populations. In the US, the prevalence of CKD increased from $14.9 \%$ in NHANES 1988 to 1994 to $17.7 \%$ in NHANES 2005 to 2008 in patients with diabetes [29]. The prevalence of CKD in patients with type 2 diabetes was $10.2 \%$ in China [30] and 15.3\% in Japan [31]. The reason for the differences among various population groups could be due to their distinct ethnicities and MDRD equation [28].

\section{HOW DO YOU DIAGNOSE DKD?}

Although there have been significant improvements in the diagnosis of DKD, it is still debatable as to the significance of microalbuminuria as a proper indicator of kidney disease. In addition, the actual proportion of DKD as a cause of CKD is questionable because there often is inaccuracy of documentation of medical diagnosis while some patients labeled with DKD may have another diagnosis such as hypertension or immunoglobulin A nephropathy [32]. In type 1 diabetes, for those with long standing diabetes, retinopathy, microalbuminuria with absence of heavy proteinuria and hematuria and with relatively preserved kidney sizes, the diagnosis of DKD can be made certainly in more than $95 \%$ of patients $[33,34]$. However, renal disease in type 2 diabetes is much more complex. The prevalence of nondiabetic renal disease with or without diabetic nephropathy is reported to be around $27 \%$ to $79 \%$ in type 2 diabetes with nephropathy [35-39]. Any types of kidney dis- ease can occur in patients with diabetes. Because of the lack of a precise diagnosis and the associated diseases as confounding factors, the clinician should bear in mind that renal disease in patients with type 2 diabetes may not be fully attributable to DKD alone. Usually diabetic patients undergo diagnostic renal biopsies only when the clinical course is not typical for diabetic nephropathy. In terms of eGFR, the equations used to estimate GFR are not accurate reflections of GFR, but rather general estimates [40] and normal aging can result in an eGFR $<60 \mathrm{~mL} /$ $\min / 1.73 \mathrm{~m}^{2}$. It would be better to select age-appropriate targets for the definition of CKD. Therefore, eGFR $<60 \mathrm{~mL} /$ $\min / 1.73 \mathrm{~m}^{2}$ is an appropriate indicator for those under 50 years of age, whereas the definition of stage 3 CKD should be eGFR $<45 \mathrm{~mL} / \mathrm{min} / 1.73 \mathrm{~m}^{2}$ for people above the age of 50 years [32]. In sum, a more accurate reflection of the impact of CKD (and DKD) is seen in ESRD data with no dispute on the number of people with dialysis or transplants [40].

Since nephrologists do not make the initial diagnosis of DKD, they rely on primary care physicians and endocrinologists to make the diagnosis. Thus, one of the major goals for nephrologists is to provide them with much in-depth education and maintain good liaison with nonnephrology physicians who care for patients with diabetes. The routine evaluation of diabetes for DKD will enable them either to provide appropriate treatment or refer to a nephrologist [32]. Referral to or at least a screening visit to a nephrologist is mandatory if eGFR is declining $\left(<45 \mathrm{~mL} / \mathrm{min} / 1.73 \mathrm{~m}^{2}\right)$ and urine albumincreatinine ratio is $>300 \mathrm{mg} / \mathrm{g}$ (or urine protein-creatinine ratio is $>0.5 \mathrm{~g} / \mathrm{g}$ ) [32]. In fact, $43 \%$ of the total patients started dialysis in the US without ever seeing a nephrologist in 2010 [40] and $38.9 \%$ of the patients who were known to have diabetes started dialysis therapy without ever being referred to a nephrologist [40]. Late referral to renal specialists is associated with increased morbidity and mortality and may result in poorer patient-related outcomes [41].

\section{HOW PREVALENT IS ESRD?}

In the US, there were about 35,000 dialysis patients and about 6,000 transplant recipients in 1978 [40]. As of 2010, there were approximately 415,000 dialysis patients and 180,000 transplant recipients. The incidence of ESRD has increased from 86.8 per million to 347 per million cases per year. Of greater importance is the fact that the incidence rates of ESRD had been increasing steadily up to 2002, but have remained almost 
stable since, although the prevalence continues to rise [40]. The reason for this slowing of incidence rate of ESRD is due to the emergence of diabetes as the major cause of renal disease. Despite an increased incidence of diabetes, many studies have supported that a person with CKD is much more likely to die of a cardiovascular event rather than surviving to receiving dialysis or a transplant for DKD in type 2 diabetes [42-45]. A recent study demonstrated that patients with diabetes with CKD compared to non-DKD have much higher death rates for the same level of GFR [42]. However, the total number of patients with ESRD continues to increase at a rapid rate with diabetes being the principal cause [44]. Fortunately, this trend might not continue because there is a recent report suggesting that this rapid increase may be slowing down [46].

In Korea, total number of patients with renal replacement therapy in 2012 was 70,211 and the prevalence of ESRD was 1,353 patients per million population [6], which was 63,341 and 1,224 patients per million population, respectively, in 2011 [6]. As of 2012, the incidence of ESRD was 221 per million cases per year and the number of new ESRD patients was

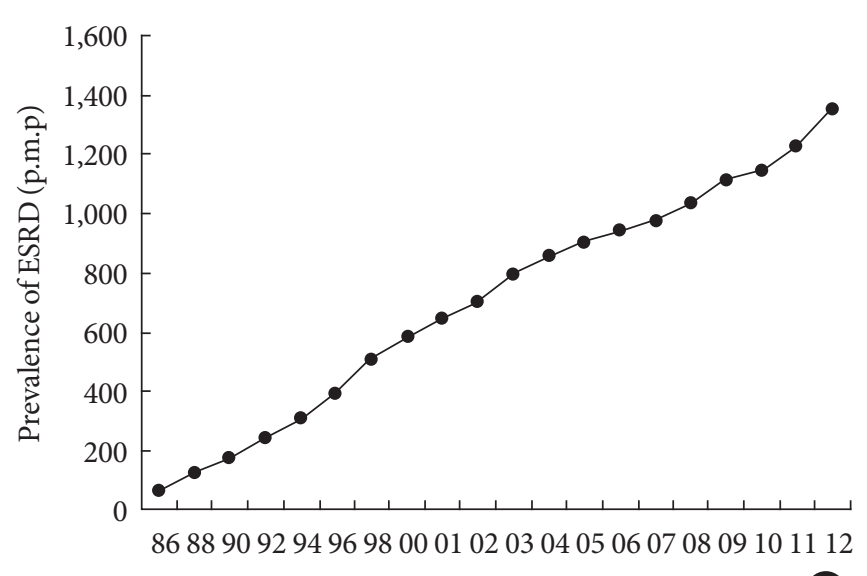

A

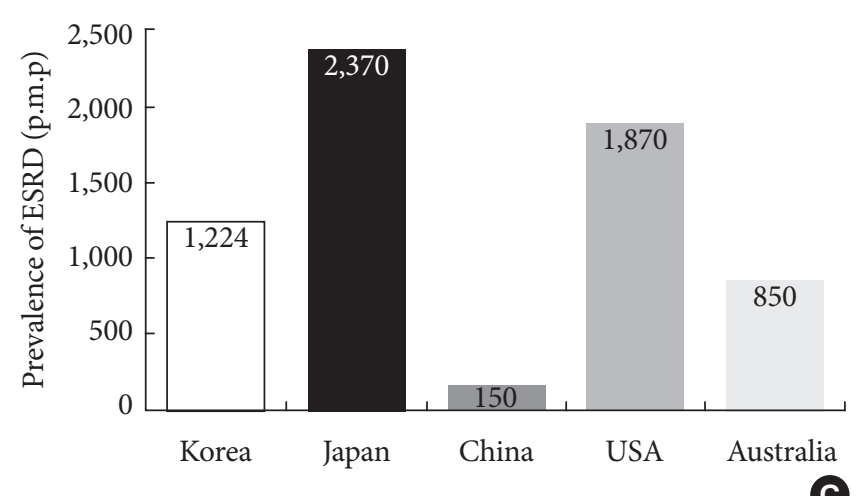

(
11,472 (Fig. 2). The most common primary cause of ESRD in 2012 was diabetic nephropathy (50.6\%) followed by hypertensive nephrosclerosis (18.5\%) and chronic glomerulonephritis (8.1\%) (Fig. 3). In contrast to the US, the total number of new patients with ESRD has steadily increased, which occurred along with an increase in the number of patients with diabetes (Fig. 3) $[6,25]$. Recent KNHANES V study showed that the prevalence of diabetes and prediabetes markedly increased when hemoglobin A1c (HbA1c) is added as a diagnostic criterion [25]. Since the proportion of diabetes and prediabetes has largely increased, the complications of diabetes including DKD will be increasing significantly as well. This trend will be much the same for the prevalence and incidence of ESRD patients. Therefore, new recommendations will be helpful for detection of patients with early diabetic nephropathy with risk of complications. The ESRD registry of Korean Society of Nephrology clearly shows that $46.9 \%$ of ESRD patients had died of cardiovascular events [6]. Thus, we should consider novel means as to how we could improve patient care by early diagnosis, aggressive and proper management of patients with dia-

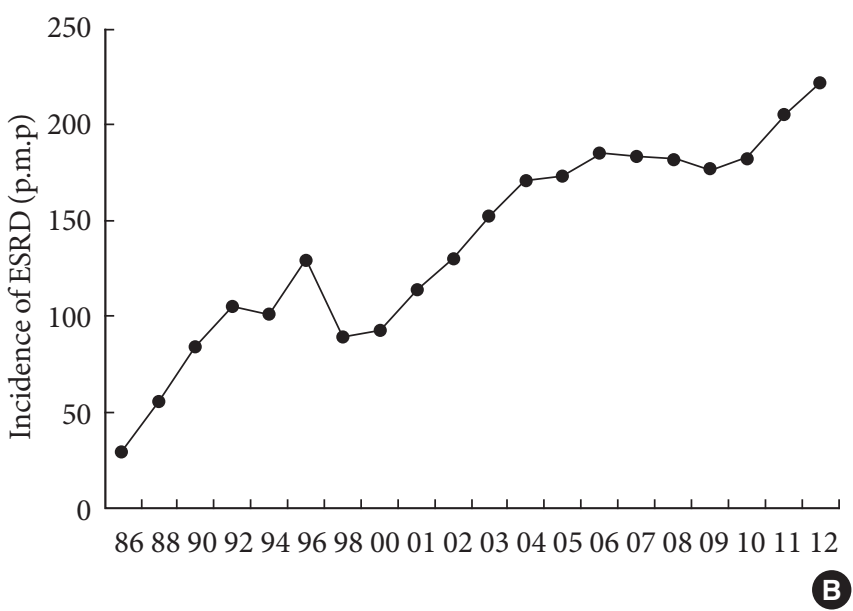

Fig. 2. The prevalence (A) and incidence (B) of end-stage renal disease (ESRD) from 1986 to 2012 among Korean adults from Insan Memorial Dialysis Registry, 2012 [6]. (C) The prevalence of ESRD in various countries including Korea, Japan, China, USA, and Australia. p.m.p., per million people. 


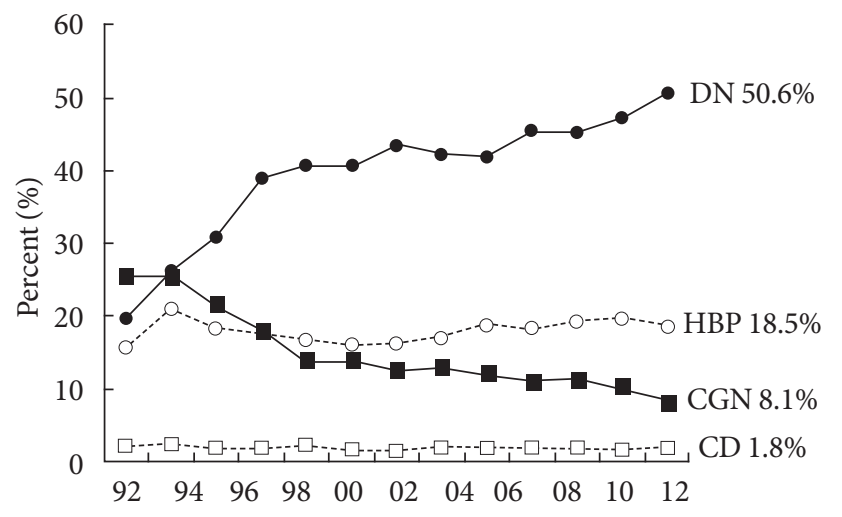

A

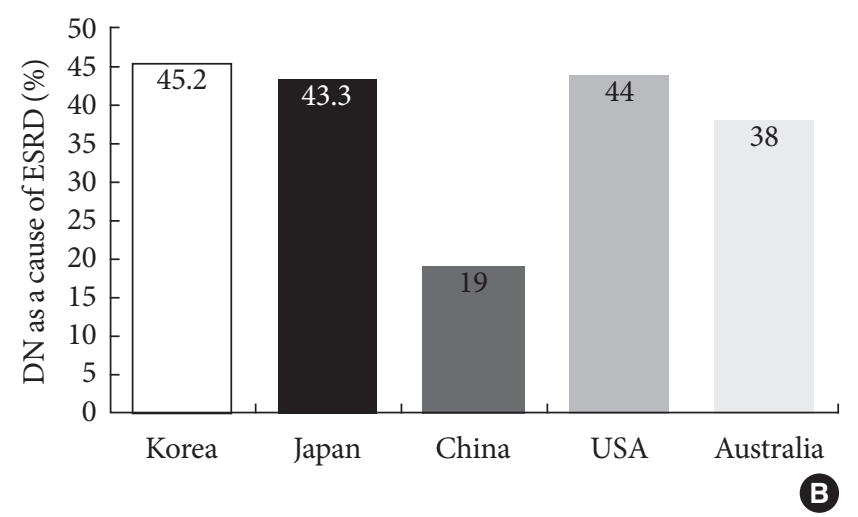

Fig. 3. (A) Four major causes of end-stage renal disease (ESRD) in Korean adult patients who initiated renal replacement therapy each year among Korean adults from Insan Memorial Dialysis Registry, 2012 [6]. (B) The incidence of diabetic nephropathy (DN) as a cause of ESRD in various countries including Korea, Japan, China, USA, and Australia in 2011. HBP, hypertensive nephropathy; CGN, chronic glomerulonephritis; CD, cystic disease.

betes.

\section{HOW TO PREVENT THE PROGRESSION OF DKD TO ESRD}

To prevent the progression of DKD and subsequent cardiovascular morbidity and mortality entailed in patients with diabetes, it is important to personalize treatment and to set treatment goals for individual patients depending on age, type of diabetes, and its duration [47]. Bearing in mind that longer duration of diabetes, poor glycemic control, presence of albuminuria, and hypertension are the common risk factors for DKD and its progression, a multilateral approach targeting these risk factors could be considered. The Steno- 2 trial showed the success of such a multifactorial approach in patients with type 2 diabetes and microalbuminuria [48]. In the Steno- 2 trial, all of the patients were treated for a mean period of 7.8 years with either conventional or intensive regimen consisting of tight glucose control (target $\mathrm{HbA1c}<6.5 \%$ ), blood pressure control with RAA system (RAAS) blockade (with its use regardless of initial blood pressure level; target blood pressure $<130 / 80 \mathrm{~mm} \mathrm{Hg}$ ), aspirin and lipid-lowering agents (target total cholesterol $<175 \mathrm{mg} / \mathrm{dL}$, fasting triglycerides $<150 \mathrm{mg} /$ dL). After 13.3 years of follow-up, intensive therapy was associated with a $20 \%$ absolute mortality risk reduction. In the intensive group, DKD (20 patients vs. 37 patients) and ESRD (1 patient vs. 6 patients) developed in fewer subjects as compared to the conventional regimen group [48]. These results showed that a multitargeted therapy can slow the progression of DKD. In addition, to potentiate the effects of RAAS blockade, sodium restriction and/or diuretics should be considered [49]. Clinical trials confirming positive effects of aldosterone blockade are also needed [50]. Korean subjects with diabetes showed that high blood pressure was significantly associated with an increased risk of albuminuria while older age, higher serum triglyceride levels, and longer diabetes duration were determinants of CKD [15]. Therefore, a multitargeted therapy might retard and slow the progression of DKD in Korean diabetic patients.

DKD is characterized by a long period of clinical silence without significant signs or symptoms. Therefore, novel methods for detecting early mediators of renal injury are needed to find out the onset of DKD at the earliest and to prevent its progression. Recently, several new targets are showing promise as markers in the prevention and treatment of early DKD in type 1 diabetes [51]. These are serum uric acid, insulin sensitivity, vasopressin, and sodium-glucose cotransport-2 inhibition which may have same roles in type 2 diabetes as well. However, further studies are required to confirm the roles of these targets in type 2 diabetes. We also try our best to identify novel and modifiable risk factors, including transforming growth factor- $\beta$, bone morphogenic growth factor- 7 in serum and urine that contribute to the development and progression of early diabetic nephropathy [52].

Advances in our understanding of the mechanisms of DKD have identified additional risk factors for nephropathy. Subse- 
quently, novel therapeutic options are being explored targeting these factors. The beneficial effects of many of the novel agents on DKD are attributed to their vascular protective factors, antifibrotic, antioxidant, anti-inflammatory, and intracellular metabolic modulatory properties [53-57]. However, many clinical trials with novel agents targeting these effects have not shown dramatic efficacy in preventing or delaying DKD [53]. Thus, continuing research is needed to look for novel therapies for DKD and thereby to reduce the morbidity and mortality associated with it.

\section{CONCLUSIONS}

ESRD is a major public health problem in Korea with diabetes being the leading cause. Significant improvements have been made in the diagnosis, prevention, and treatment of diabetes that have contributed to slow progression of the disease and to prevent the cardiovascular complications. On the contrary, the risk of ESRD in patients with diabetes is not decreasing but it is increasing continually. The principal goals of the health care system should focus on the prevention and slowing of progression of CKD resulting from diabetes and health-care providers including nephrologists and endocrinologists are required to determine the best approach for both diagnosis and management [32].

It is very important that the nephrology community provides leadership in early diagnosis, best and aggressive management, cost-effective interventions, and education to slow down the DKD epidemic. Furthermore, research into novel therapies to treat diabetic nephropathy is an urgent need aiming at the prevention and management of DKD and this should be preceded by appropriate understanding of the prevalence and the nature of diabetic nephropathy. Clearly, tremendous additional experimental efforts will be needed to uncover the complex pathogenesis of diabetes and its cardiovascular complications.

\section{CONFLICTS OF INTEREST}

No potential conflict of interest relevant to this article was reported.

\section{ACKNOWLEDGMENTS}

The author would like to thank Dr. Yaeni Kim for her valuable support in making this manuscript.

\section{REFERENCES}

1. Hunsicker LG. The consequences and costs of chronic kidney disease before ESRD. J Am Soc Nephrol 2004;15:1363-4.

2. Go AS, Chertow GM, Fan D, McCulloch CE, Hsu CY. Chronic kidney disease and the risks of death, cardiovascular events, and hospitalization. N Engl J Med 2004;351:1296-305.

3. Foley RN, Murray AM, Li S, Herzog CA, McBean AM, Eggers PW, Collins AJ. Chronic kidney disease and the risk for cardiovascular disease, renal replacement, and death in the United States Medicare population, 1998 to 1999. J Am Soc Nephrol 2005;16:489-95.

4. Madan P, Kalra OP, Agarwal S, Tandon OP. Cognitive impairment in chronic kidney disease. Nephrol Dial Transplant 2007; 22:440-4.

5. Chin HJ, Song YR, Lee JJ, Lee SB, Kim KW, Na KY, Kim S, Chae DW. Moderately decreased renal function negatively affects the health-related quality of life among the elderly Korean population: a population-based study. Nephrol Dial Transplant 2008;23:2810-7.

6. Jin DC, Han JS. Renal replacement therapy in Korea, 2012. Kidney Res Clin Pract 2014;33:9-18.

7. United States Renal Data System: USRDS Annual Data Report. National Institute of Diabetes and Digestive and Kidney Diseases, 2013. Available from: www.usrds.org (updated 2014 May $1)$.

8. Coresh J, Selvin E, Stevens LA, Manzi J, Kusek JW, Eggers P, Van Lente F, Levey AS. Prevalence of chronic kidney disease in the United States. JAMA 2007;298:2038-47.

9. Chadban SJ, Briganti EM, Kerr PG, Dunstan DW, Welborn TA, Zimmet PZ, Atkins RC. Prevalence of kidney damage in Australian adults: the AusDiab kidney study. J Am Soc Nephrol 2003;14(7 Suppl 2):S131-8.

10. Imai E, Horio M, Watanabe T, Iseki K, Yamagata K, Hara S, Ura N, Kiyohara Y, Moriyama T, Ando Y, Fujimoto S, Konta T, Yokoyama H, Makino H, Hishida A, Matsuo S. Prevalence of chronic kidney disease in the Japanese general population. Clin Exp Nephrol 2009;13:621-30.

11. Zhang L, Zhang P, Wang F, Zuo L, Zhou Y, Shi Y, Li G, Jiao S, Liu Z, Liang W, Wang H. Prevalence and factors associated with CKD: a population study from Beijing. Am J Kidney Dis 2008;51:373-84.

12. Nagata M, Ninomiya T, Doi Y, Yonemoto K, Kubo M, Hata J, 
Tsuruya K, Iida M, Kiyohara Y. Trends in the prevalence of chronic kidney disease and its risk factors in a general Japanese population: the Hisayama Study. Nephrol Dial Transplant 2010;25:2557-64.

13. Chin HJ, Ahn JM, Na KY, Chae DW, Lee TW, Heo NJ, Kim S. The effect of the World Kidney Day campaign on the awareness of chronic kidney disease and the status of risk factors for cardiovascular disease and renal progression. Nephrol Dial Transplant 2010;25:413-9.

14. Kang HT, Lee J, Linton JA, Park BJ, Lee YJ. Trends in the prevalence of chronic kidney disease in Korean adults: the Korean National Health and Nutrition Examination Survey from 1998 to 2009. Nephrol Dial Transplant 2013;28:927-36.

15. Ahn JH, Yu JH, Ko SH, Kwon HS, Kim DJ, Kim JH, Kim CS, Song KH, Won JC, Lim S, Choi SH, Han K, Cha BY, Kim NH; Taskforce Team of Diabetes Fact Sheet of the Korean Diabetes Association. Prevalence and determinants of diabetic nephropathy in Korea: Korea national health and nutrition examination survey. Diabetes Metab J 2014;38:109-19.

16. Chong YB, Keng TC, Tan LP, Ng KP, Kong WY, Wong CM, Cheah PL, Looi LM, Tan SY. Clinical predictors of non-diabetic renal disease and role of renal biopsy in diabetic patients with renal involvement: a single centre review. Ren Fail 2012;34:323-8.

17. Villar E, Polkinghorne KR, Chang SH, Chadban SJ, McDonald SP. Effect of type 2 diabetes on mortality risk associated with end-stage kidney disease. Diabetologia 2009;52:2536-41.

18. Gross JL, de Azevedo MJ, Silveiro SP, Canani LH, Caramori ML, Zelmanovitz T. Diabetic nephropathy: diagnosis, prevention, and treatment. Diabetes Care 2005;28:164-76.

19. Ritz E, Orth SR. Nephropathy in patients with type 2 diabetes mellitus. N Engl J Med 1999;341:1127-33.

20. Young BA, Katon WJ, Von Korff M, Simon GE, Lin EH, Ciechanowski PS, Bush T, Oliver M, Ludman EJ, Boyko EJ. Racial and ethnic differences in microalbuminuria prevalence in a diabetes population: the pathways study. J Am Soc Nephrol 2005;16:219-28.

21. Parving HH, Lewis JB, Ravid M, Remuzzi G, Hunsicker LG, investigators D. Prevalence and risk factors for microalbuminuria in a referred cohort of type II diabetic patients: a global perspective. Kidney Int 2006;69:2057-63.

22. Wild S, Roglic G, Green A, Sicree R, King H. Global prevalence of diabetes: estimates for the year 2000 and projections for 2030. Diabetes Care 2004;27:1047-53.

23. Danaei G, Finucane MM, Lu Y, Singh GM, Cowan MJ, Paciorek CJ, Lin JK, Farzadfar F, Khang YH, Stevens GA, Rao M, Ali
MK, Riley LM, Robinson CA, Ezzati M; Global Burden of Metabolic Risk Factors of Chronic Diseases Collaborating Group (Blood Glucose). National, regional, and global trends in fasting plasma glucose and diabetes prevalence since 1980: systematic analysis of health examination surveys and epidemiological studies with 370 country-years and 2.7 million participants. Lancet 2011;378:31-40.

24. Centers for Disease Control and Prevention: Diabetes report card 2012: national and state profile of diabetes and its complications. Available from: http://www.cdc.gov/diabetes/pubs/reportcard.htm (Updated 2013 Apr 3).

25. Jeon JY, Ko SH, Kwon HS, Kim NH, Kim JH, Kim CS, Song KH, Won JC, Lim S, Choi SH, Jang MJ, Kim Y, Oh K, Kim DJ, Cha BY; Taskforce Team of Diabetes Fact Sheet of the Korean Diabetes Association. Prevalence of diabetes and prediabetes according to fasting plasma glucose and HbAlc. Diabetes Metab J 2013;37:349-57.

26. Jia W, Gao X, Pang C, Hou X, Bao Y, Liu W, Wang W, Zuo Y, $\mathrm{Gu} \mathrm{H}$, Xiang K. Prevalence and risk factors of albuminuria and chronic kidney disease in Chinese population with type 2 diabetes and impaired glucose regulation: Shanghai diabetic complications study (SHDCS). Nephrol Dial Transplant 2009;24: 3724-31.

27. Lee KU, Park JY, Kim SW, Lee MH, Kim GS, Park SK, Park JS. Prevalence and associated features of albuminuria in Koreans with NIDDM. Diabetes Care 1995;18:793-9.

28. Yang CW, Park JT, Kim YS, Kim YL, Lee YS, Oh YS, Kang SW. Prevalence of diabetic nephropathy in primary care type 2 diabetic patients with hypertension: data from the Korean Epidemiology Study on Hypertension III (KEY III study). Nephrol Dial Transplant 2011;26:3249-55.

29. de Boer IH, Rue TC, Hall YN, Heagerty PJ, Weiss NS, Himmelfarb J. Temporal trends in the prevalence of diabetic kidney disease in the United States. JAMA 2011;305:2532-9.

30. Chen W, Chen W, Wang H, Dong X, Liu Q, Mao H, Tan J, Lin J, Zhou F, Luo N, He H, Johnson RJ, Zhou SF, Yu X. Prevalence and risk factors associated with chronic kidney disease in an adult population from southern China. Nephrol Dial Transplant 2009;24:1205-12.

31. Yokoyama H, Sone H, Oishi M, Kawai K, Fukumoto Y, Kobayashi M; Japan Diabetes Clinical Data Management Study Group. Prevalence of albuminuria and renal insufficiency and associated clinical factors in type 2 diabetes: the Japan Diabetes Clinical Data Management study (JDDM15). Nephrol Dial Transplant 2009;24:1212-9. 
32. Stanton RC. Clinical challenges in diagnosis and management of diabetic kidney disease. Am J Kidney Dis 2014;63(2 Suppl 2):S3-21.

33. Kramer HJ, Nguyen QD, Curhan G, Hsu CY. Renal insufficien$\mathrm{cy}$ in the absence of albuminuria and retinopathy among adults with type 2 diabetes mellitus. JAMA 2003;289:3273-7.

34. Mauer SM, Chavers BM, Steffes MW. Should there be an expanded role for kidney biopsy in the management of patients with type I diabetes? Am J Kidney Dis 1990;16:96-100.

35. Mak SK, Gwi E, Chan KW, Wong PN, Lo KY, Lee KF, Wong AK. Clinical predictors of non-diabetic renal disease in patients with non-insulin dependent diabetes mellitus. Nephrol Dial Transplant 1997;12:2588-91.

36. Tone A, Shikata K, Matsuda M, Usui H, Okada S, Ogawa D, Wada J, Makino $\mathrm{H}$. Clinical features of non-diabetic renal diseases in patients with type 2 diabetes. Diabetes Res Clin Pract 2005;69:237-42.

37. Caramori ML, Fioretto P, Mauer M. The need for early predictors of diabetic nephropathy risk: is albumin excretion rate sufficient? Diabetes 2000;49:1399-408.

38. Lin YL, Peng SJ, Ferng SH, Tzen CY, Yang CS. Clinical indicators which necessitate renal biopsy in type 2 diabetes mellitus patients with renal disease. Int J Clin Pract 2009;63:1167-76.

39. Wong TY, Choi PC, Szeto CC, To KF, Tang NL, Chan AW, Li PK, Lai FM. Renal outcome in type 2 diabetic patients with or without coexisting nondiabetic nephropathies. Diabetes Care 2002;25:900-5.

40. Collins AJ, Foley RN, Herzog C, Chavers B, Gilbertson D, Herzog C, Ishani A, Johansen K, Kasiske B, Kutner N, Liu J, St Peter W, Ding S, Guo H, Kats A, Lamb K, Li S, Li S, Roberts T, Skeans M, Snyder J, Solid C, Thompson B, Weinhandl E, Xiong H, Yusuf A, Zaun D, Arko C, Chen SC, Daniels F, Ebben J, Frazier E, Hanzlik C, Johnson R, Sheets D, Wang X, Forrest B, Constantini E, Everson S, Eggers P, Agodoa L. US renal data system 2012 annual data report. Am J Kidney Dis 2013;61(1 Suppl 1):A7,e1476.

41. Navaneethan SD, Nigwekar S, Sengodan M, Anand E, Kadam S, Jeevanantham V, Grieff M, Choudhry W. Referral to nephrologists for chronic kidney disease care: is non-diabetic kidney disease ignored? Nephron Clin Pract 2007;106:c113-8.

42. Afkarian M, Sachs MC, Kestenbaum B, Hirsch IB, Tuttle KR, Himmelfarb J, de Boer IH. Kidney disease and increased mortality risk in type 2 diabetes. J Am Soc Nephrol 2013;24:302-8.

43. Jude EB, Anderson SG, Cruickshank JK, Srivatsa A, Tentolouris N, Chandrasekaran R, Gokal R, Boulton AJ. Natural history and prognostic factors of diabetic nephropathy in type 2 diabetes. QJM 2002;95:371-7.

44. Muntner P, Bowling CB, Gao L, Rizk D, Judd S, Tanner RM, McClellan W, Warnock DG. Age-specific association of reduced estimated glomerular filtration rate and albuminuria with all-cause mortality. Clin J Am Soc Nephrol 2011;6:2200-7.

45. Ninomiya T, Perkovic V, de Galan BE, Zoungas S, Pillai A, Jardine M, Patel A, Cass A, Neal B, Poulter N, Mogensen CE, Cooper M, Marre M, Williams B, Hamet P, Mancia G, Woodward M, Macmahon S, Chalmers J; ADVANCE Collaborative Group. Albuminuria and kidney function independently predict cardiovascular and renal outcomes in diabetes. J Am Soc Nephrol 2009;20:1813-21.

46. Couchoud C, Villar E. End-stage renal disease epidemic in diabetics: is there light at the end of the tunnel? Nephrol Dial Transplant 2013;28:1073-6.

47. Waanders F, Visser FW, Gans RO. Current concepts in the management of diabetic nephropathy. Neth J Med 2013;71: 448-58.

48. Gaede P, Lund-Andersen H, Parving HH, Pedersen O. Effect of a multifactorial intervention on mortality in type 2 diabetes. N Engl J Med 2008;358:580-91.

49. Esnault VL, Ekhlas A, Delcroix C, Moutel MG, Nguyen JM. Diuretic and enhanced sodium restriction results in improved antiproteinuric response to RAS blocking agents. J Am Soc Nephrol 2005;16:474-81.

50. Sato A, Hayashi K, Naruse M, Saruta T. Effectiveness of aldosterone blockade in patients with diabetic nephropathy. Hypertension 2003;41:64-8.

51. Bjornstad P, Cherney D, Maahs DM. Early diabetic nephropathy in type 1 diabetes: new insights. Curr Opin Endocrinol Diabetes Obes 2014;21:279-86.

52. de Zeeuw D, Akizawa T, Audhya P, Bakris GL, Chin M, ChristSchmidt H, Goldsberry A, Houser M, Krauth M, Lambers Heerspink HJ, McMurray JJ, Meyer CJ, Parving HH, Remuzzi G, Toto RD, Vaziri ND, Wanner C, Wittes J, Wrolstad D, Chertow GM; BEACON Trial Investigators. Bardoxolone methyl in type 2 diabetes and stage 4 chronic kidney disease. N Engl J Med 2013;369:2492-503.

53. Mima A, Qi W, King GL. Implications of treatment that target protective mechanisms against diabetic nephropathy. Semin Nephrol 2012;32:471-8.

54. Chung S, Park CW. Role of peroxisome proliferator-activated receptor alpha in diabetic nephropathy. Diabetes Metab J 2011;35:327-36. 
55. Fineberg D, Jandeleit-Dahm KA, Cooper ME. Diabetic nephropathy: diagnosis and treatment. Nat Rev Endocrinol 2013;9:713-23.

56. Higgins GC, Coughlan MT. Mitochondrial dysfunction and mitophagy: the beginning and end to diabetic nephropathy?
Br J Pharmacol 2014;171:1917-42.

57. Mima A. Inflammation and oxidative stress in diabetic nephropathy: new insights on its inhibition as new therapeutic targets. J Diabetes Res 2013;2013:248563. 